\title{
Targeting triple-negative breast cancers with the Smac-mimetic birinapant
}

\author{
Najoua Lalaoui $\mathbb{D}^{1,2} \cdot$ Delphine Merino $\mathbb{B}^{1,2,3} \cdot$ Goknur Giner $^{1,2} \cdot$ François Vaillant $\mathbb{D}^{1,2} \cdot$ Diep Chau ${ }^{1} \cdot$ Lin Liu $^{1,2}$. \\ Tobias Kratina ${ }^{1}$ - Bhupinder Pal $\mathbb{1}^{1,2,3} \cdot$ James R. Whittle ${ }^{1,2} \cdot$ Nima Etemadi $\mathbb{D}^{1,2,3} \cdot$ Jean Berthelet ${ }^{3}$ - Julius Gräsel ${ }^{1,2}$. \\ Cathrine Hall ${ }^{1}$ Matthew E. Ritchie $\mathbb{1}^{1,2} \cdot$ Matthias Ernst $\mathbb{D}^{3} \cdot$ Gordon K. Smyth $\mathbb{D}^{1,2,4} \cdot$ David L. Vaux $\mathbb{D}^{1,2} \cdot$ \\ Jane E. Visvader ${ }^{1,2} \cdot$ Geoffrey J. Lindeman $\mathbb{D}^{1,5,6} \cdot$ John Silke $\mathbb{D}^{1,2}$
}

Received: 10 June 2019 / Revised: 22 February 2020 / Accepted: 1 April 2020 / Published online: 27 April 2020

(c) The Author(s), under exclusive licence to ADMC Associazione Differenziamento e Morte Cellulare 2020. This article is published with open access

\begin{abstract}
Smac mimetics target inhibitor of apoptosis (IAP) proteins, thereby suppressing their function to facilitate tumor cell death. Here we have evaluated the efficacy of the preclinical Smac-mimetic compound A and the clinical lead birinapant on breast cancer cells. Both exhibited potent in vitro activity in triple-negative breast cancer (TNBC) cells, including those from patient-derived xenograft (PDX) models. Birinapant was further studied using in vivo PDX models of TNBC and estrogen receptor-positive $\left(\mathrm{ER}^{+}\right)$breast cancer. Birinapant exhibited single agent activity in all TNBC PDX models and augmented response to docetaxel, the latter through induction of TNF. Transcriptomic analysis of TCGA datasets revealed that genes encoding mediators of Smac-mimetic-induced cell death were expressed at higher levels in TNBC compared with ER ${ }^{+}$ breast cancer, resulting in a molecular signature associated with responsiveness to Smac mimetics. In addition, the cell death complex was preferentially formed in TNBCs versus $\mathrm{ER}^{+}$cells in response to Smac mimetics. Taken together, our findings provide a rationale for prospectively selecting patients whose breast tumors contain a competent death receptor signaling pathway for the further evaluation of birinapant in the clinic.
\end{abstract}

\section{Introduction}

These authors contributed equally: Delphine Merino, Goknur Giner, François Vaillant

These authors jointly supervised this work: Jane E. Visvader, Geoffrey J. Lindeman, John Silke

\section{Edited by G. Melino}

Supplementary information The online version of this article (https:// doi.org/10.1038/s41418-020-0541-0) contains supplementary material, which is available to authorized users.

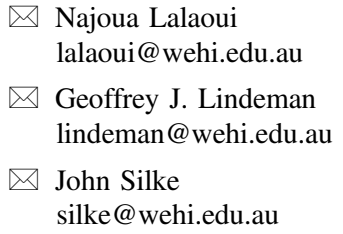

1 The Walter and Eliza Hall Institute of Medical Research, Parkville, VIC 3052, Australia

2 Department of Medical Biology, University of Melbourne, Parkville, VIC 3010, Australia
Breast cancer can be categorized into at least five subtypes based on their gene expression profiles [1-5]. Although molecular profiling has contributed to a greater understanding of breast tumor biology, therapeutic approaches are still largely guided by the presence or absence of three biomarkers: estrogen receptor (ER), progesterone receptor (PR), and human epidermal growth factor receptor 2 (HER2) amplification, which broadly divide breast cancer into three

3 Olivia Newton-John Cancer Research Institute and School for Cancer Medicine La Trobe University, Heidelberg, VIC 3084, Australia

4 School of Mathematics and Statistics, University of Melbourne, Parkville, VIC 3010, Australia

5 Department of Medical Oncology, Peter MacCallum Cancer Centre, Melbourne, VIC 3000, Australia

6 Department of Medicine, Royal Melbourne Hospital, University of Melbourne, Parkville, VIC 3010, Australia 
groups: luminal $\left(\mathrm{ER}^{+}\right.$and $\mathrm{PR}^{+}$or $\left.\mathrm{PR}^{-}\right), \mathrm{HER} 2$-amplified, and triple-negative breast cancer (TNBC), which lacks ER, PR, and HER2 expression [6]. The identification of these biomarkers has assisted the development of targeted therapies that include endocrine therapy (such as tamoxifen or aromatase inhibitors) or anti-HER2 therapy (such as trastuzumab), which have considerably improved survival for women with early and relapsed breast cancer [7, 8]. In contrast, treatment for TNBC still presents a major clinical challenge due to the paucity of useful molecular targets. Apart from patients harboring BRCA1/2 mutations, where poly (ADP-ribose) polymerase (PARP) inhibitors have recently shown benefit, therapeutic options for patients with TNBC are largely restricted to surgery plus conventional systemic cytotoxic chemotherapy. Recently, Pprogrammed death-ligand 1 (PD-L1) expression has been shown to be a useful biomarker of response to immunotherapy [9]. Therefore, the identification of additional molecular targets for TNBC patients remains an important area of unmet need.

Smac mimetics have emerged as a promising class of targeted therapies that are currently being tested in the clinic for solid and hematological cancers [10]. These drugs suppress the function of inhibitor of apoptosis (IAP) proteins, whose expression is associated with tumorigenesis, chemoresistance, disease progression, and poor prognosis [11]. The key IAP members-XIAP, cIAP1, and cIAP2bear three tandem baculoviral IAP repeat domains (BIRs) and a C-terminal E3 ligase RING domain. Smac/DIABLO is a natural IAP antagonist protein that, when released from the mitochondria during apoptosis, binds to IAPs [12, 13]. Smac-mimetic compounds are modeled on the N-terminal AVPI tetrapeptide of Smac/DIABLO, which binds to the BIR domains of IAPs, and mimic the inhibitory activity of endogenous Smac/DIABLO.

The development of Smac-mimetic compounds has helped to reveal the role for IAPs in regulating TNF receptor signaling. Binding of TNF to its receptor TNFR1 recruits proteins including cIAP1/2, which conjugate ubiquitin chains to RIPK1, culminating in the activation of NF$\kappa \mathrm{B}$ and MAPK signaling pathways [10]. Inhibition of cIAP1/2 by Smac mimetics reduces the ubiquitylation of RIPK1 and the expression of survival genes such as CFLAR encoding cFLIP [10]. Consequently, deubiquitylated RIPK1 binds to caspase-8 to form a deadly cytosolic molecular platform called complex II. Caspase- 8 is activated within this complex and cleaves RIPK1 and caspase-3 to induce apoptosis. In some circumstances, caspase- 8 activity is insufficient to prevent the formation of a secondary complex consisting of uncleaved RIPK1 and RIPK3, which phosphorylates and activates MLKL to induce necroptosis [14]. By preventing cIAP1/TRAF2/TRAF3-mediated degradation of NF- $\kappa \mathrm{B}$-inducing kinase (NIK), Smac mimetics also induce autocrine secretion of TNF [15-17], and this can further promote cell death in response to Smac mimetics. In contrast to cIAP1/2, XIAP exhibits its antiapoptotic activity through direct binding to and inhibition of caspase-3, -7, and -9 [18]. The binding of Smac mimetics to XIAP's BIR domains prevents XIAP from directly binding to and inhibiting caspases-3, -7 , and -9 .

To date, several Smac-mimetic compounds are undergoing investigation in early-phase clinical trials across a range of malignancies including breast cancer [19]. The Smac-mimetic LCL161 (Novartis) has been studied in combination with paclitaxel in a randomized phase II neoadjuvant study in TNBC, where higher pathological Clinical Responses were observed in patients with a TNF $\alpha$ gene expression signature (GS), albeit with significant toxicity. This signature, derived through in silico analysis of LCL161-sensitive versus refractory cell lines, features high $T N F$ and RIPK 1 expression and is present in $26 \%$ of TNBC [20]. However, it is unknown whether other Smac mimetics like birinapant (TetraLogic Pharmaceuticals/Medivir) elicit similar tumor responses or toxicity. In addition, the molecular mechanisms underlying responsiveness remain to be fully elucidated.

Smac mimetics appear efficacious in some breast cancer cell lines when administrated alone or in combination with death ligands or chemotherapeutic drugs [21]. Breast cancer cell lines exhibit different responses to Smac mimetics [21], suggesting that expression profiles and/or breast cancer subtypes might determine Smac-mimetic responsiveness. In this study, we sought to determine the molecular mechanisms underlying the responsiveness of two breast cancer subtypes to birinapant. We found that birinapant was more potent in TNBC compared with $\mathrm{ER}^{+}$breast cancer cells using primary patient-derived xenografts (PDX) in vitro. Importantly, birinapant was also efficacious in vivo in TNBC PDX models. Protein expression profiling revealed that cIAP1 levels were higher in $\mathrm{ER}^{+}$than TNBC. However, this subtype remained largely resistant to induced cell death, even though birinapant was able to degrade most of cIAP1 in $\mathrm{ER}^{+}$breast cancer cells. Gene expression profiling further revealed that TNBCs express higher levels of TNF and other genes encoding activators of Smac-mimeticinduced cell death. Together, our findings reveal a targetable subset of breast cancers that include TNBC and possibly some $\mathrm{ER}^{+}$breast cancers.

\section{Results}

\section{TNBC PDX tumors are responsive to the Smac-mimetic birinapant}

To test the sensitivity of breast cancers to IAP inhibition, we evaluated the potency of two bivalent Smac mimetics on 
a

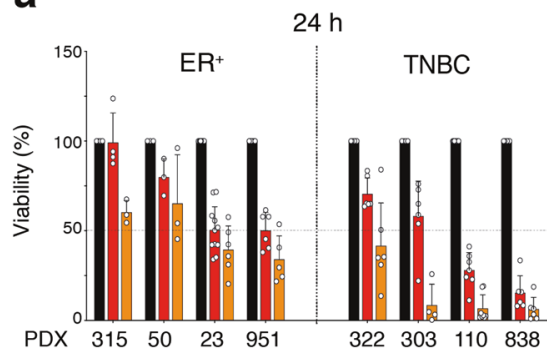

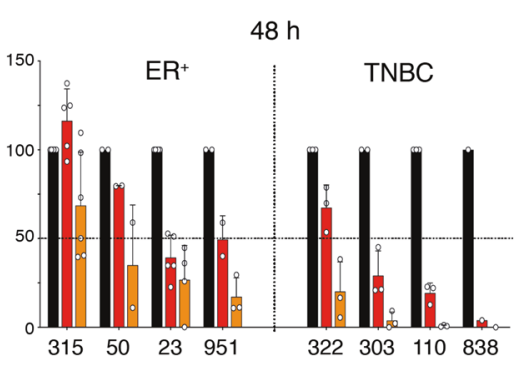

b

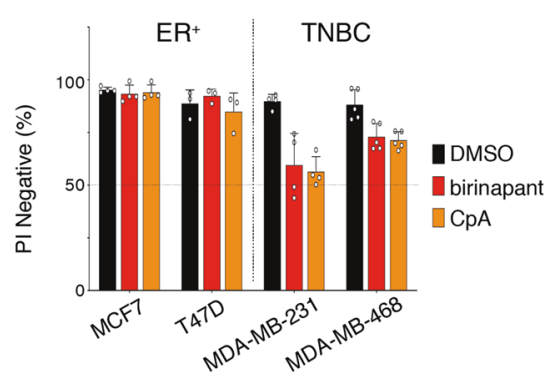

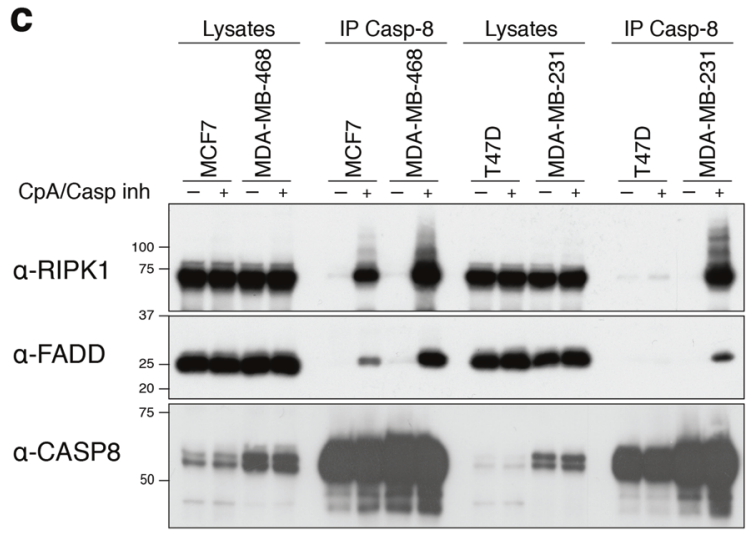

Fig. 1 TNBC are highly sensitive to Smac mimetics. a Cell viability using CellTiter-Glo of the indicated $\mathrm{ER}^{+}$and TNBC PDX tumor cells treated for 24 or $48 \mathrm{~h}$ with $1 \mu \mathrm{M}$ of birinapant or CompA (CpA) in mammosphere medium. b Cell viability assessed by measurement of Propidium iodide (PI) negative cells by flow cytometry of indicated breast cancer cell lines treated for $24 \mathrm{~h}$ with $1 \mu \mathrm{M}$ of birinapant or CompA (CpA). c Western blot analysis of complex II/Ripoptosome using anti-caspase- 8 antibody. Cells were treated for $5 \mathrm{~h}$ with $1 \mu \mathrm{M}$ of CompA $(\mathrm{CpA})$ and with $5 \mu \mathrm{M}$ of the caspase inhibitor IDN-6556

primary breast cancer tumors. Using a short-term tumor sphere assay [22], we tested the preclinical pan-IAP Smacmimetic Compound A (CpA) and the clinical lead compound birinapant on a panel of $\mathrm{ER}^{+}$and TNBC PDX models. All tumors were sensitive to CpA-induced killing over $24 \mathrm{~h}$, most notably the TNBC models (Fig. 1a). Although birinapant is a less potent inhibitor of XIAP and cIAP2 than CompA [23], PDX cells were also sensitive to this drug. In most cases, Smac-mimetic-mediated cell death requires the presence and/or secretion of autocrine TNF or another death ligand [15-17, 24-26]. Therefore, we determined cell viability at $48 \mathrm{~h}$ to provide ample time for an autocrine ligand to be secreted and mediate cell killing. At this time-point, treatment produced substantial cell death in TNBC PDX tumor cells (Fig. 1a). The TNBC cell lines MDA-MB-231 and MDA-MB-468 also exhibited sensitivity to Smac mimetics, while $\mathrm{ER}^{+}$MCF-7 and T47D breast cancer cells appeared refractory (Fig. 1b). Consistent with these findings, formation of the cell death complex was limited in $\mathrm{ER}^{+}$compared with TNBC cell lines (Fig. 1c). d

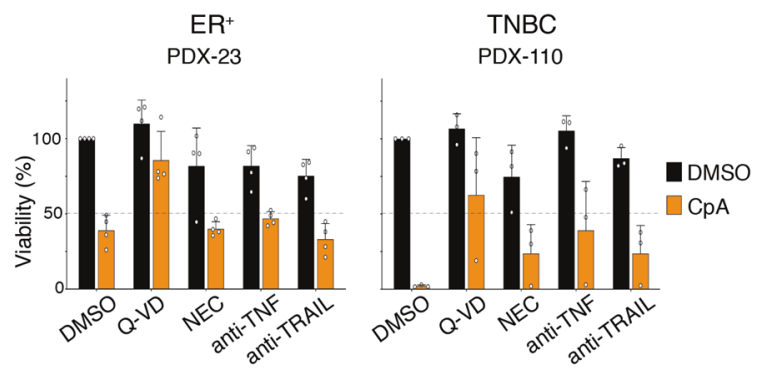

(Casp inh) to stabilize the complex. d Cell viability assessed using CellTiter-Glo of the ER ${ }^{+}$PDX-23 and the TNBC PDX-110 tumor cells treated for $24 \mathrm{~h}$ with $1 \mu \mathrm{M}$ CompA $(\mathrm{CpA}) \pm 10 \mu \mathrm{M}$ of Q-VD-OPh (Q-VD) or $50 \mu \mathrm{M}$ Necrostatin (NEC) or $10 \mu \mathrm{g} / \mathrm{ml}$ of blocking antiTNF or $10 \mu \mathrm{g} / \mathrm{ml}$ of blocking anti-TRAIL. a, b, d Results are presented as percentages of untreated cells. Bars are means $\pm \mathrm{SD} ; n=1-6$ independent tumors per PDX and $n=3-5$ independent experiments for cell lines. Each dot represents an independent tumor or an independent experiment.

Treatment with a Smac-mimetic can cause either caspasedependent apoptosis or trigger RIPK1/RIPK3-dependent necroptosis [27]. To explore the mechanism underpinning Smac-mimetic-induced cell death in PDX-derived spheres, we used the pan-caspase inhibitor, Q-VD-OPh and the RIPK1 inhibitor, necrostatin. Inhibition of RIPK1 partially protected against Smac-mimetic-induced cell death in PDX110, whereas Q-VD-OPh substantially blocked cell death induced by the Smac-mimetic in both PDX models (Fig. 1d). These findings suggest that Smac mimetics primarily kill breast cancer cells by caspase-dependent apoptosis. Consistent with the known mechanism of action of Smac mimetics, both TNF and TRAIL neutralizing antibodies reduced Smac-mimetic killing in the TNBC PDX-110, suggesting that both autocrine TNF and TRAIL contribute to Smac-mimetic-induced killing (Fig. 1d).

We next evaluated the in vivo response to the clinical compound birinapant in PDX models, including two $\mathrm{ER}^{+}$ models and three TNBC models. Mice were treated with birinapant $(30 \mathrm{mg} / \mathrm{kg}$ i.p.) three times per week for up to 
seven weeks. Therapy was well-tolerated, with mice maintaining normal body weight during therapy (not shown), and no perturbation of full blood count was observed following birinapant therapy (Supplementary Fig. 1). Similar to responses observed in vitro, birinapant did not impact on tumor growth of the PDX-315 $\mathrm{ER}^{+}$ model but significantly attenuated the growth of PDX-23 and all three TNBC models (PDX-110, -838, and -322), accompanied by significant improvement in survival to ethical endpoint (Fig. 2 and Supplementary Fig. 2). Together these data suggest that TNBCs are more sensitive to killing by Smac mimetics than $\mathrm{ER}^{+}$tumors.

\section{cIAP1 is differentially expressed between $\mathrm{ER}^{+}$and TNBC tumors}

Smac mimetics bind to the BIR domains of IAPs and thereby inhibit their function. In the case of cIAP, Smac mimetics induce auto-ubiquitylation and consequent degradation by the proteasome $[15,17]$. Because CompA and birinapant are structurally similar, but have different affinities to the IAPs, we evaluated expression of their targets cIAP1, cIAP2, and XIAP in $\mathrm{ER}^{+}$and TNBC PDX tumors to understand the differential responsiveness of the breast cancer subtypes to Smac mimetics. There were no major differences in XIAP levels between $\mathrm{ER}^{+}$and TNBC PDX tumors and cIAP2 was undetectable in most tumors (Fig. 3a). This is consistent with the observation that cIAP2 is a gene induced in response to NF- $\mathrm{KB}$ activation [28, 29]. Notably, however, much lower levels of cIAP1 were observed in TNBC PDX tumors compared with $\mathrm{ER}^{+} \mathrm{PDX}$ models (Fig. 3a). It is possible that the higher cIAP1 level in $\mathrm{ER}^{+}$tumors accounted for their relative resistance to Smac mimetics. Despite the high level of cIAP1 in PDX-23, birinapant effectively induced cIAP1 degradation within $2 \mathrm{~h}$ (Fig. 3b).

cIAP1/2 are known to promote activation of canonical NF- $\mathrm{BB}$ signaling in response to TNF, while inhibiting spontaneous activation of the noncanonical NF- $\mathrm{kB}$ signaling pathway by constitutively degrading the upstream activating kinase, NIK [15, 17, 30]. Thus, inhibition of cIAP1/2 by Smac mimetics results in the processing of NF-kB2 p100 into p52, causing transcription of NF- $\mathrm{KB}$ dependent genes, including cIAP2. Consistent with this, treatment of both $\mathrm{ER}^{+}$ and TNBC cell lines with the Smac-mimetic CpA-induced stabilization of NIK and consequent processing of p100 into p52 (Fig. 3c). Although NIK accumulation was higher in TNBC cells, the magnitude of p100 processing was similar in both $\mathrm{ER}^{+}$and TNBC cell lines (Fig. 3c). Accordingly, we found that levels of $c I A P 2$ transcripts increased after Smacmimetic treatment in both $\mathrm{ER}^{+}$and $\mathrm{TNBC}$ cell lines (Fig. 3d). Despite the ability of Smac mimetics to activate the noncanonical NF- $\mathrm{KB}$ pathway in $\mathrm{ER}^{+}$breast cancer subtypes, both birinapant and $\mathrm{CpA}$ were more effective in activating caspases and inducing cell death in TNBC cell lines, consistent with formation of the larger complex II in TNBC cells (Figs. 1a-c and 3e).

\section{A gene expression signature in TNBC containing mediators of Smac-mimetic killing}

Smac mimetics function by inhibiting IAPs but also require the expression of other downstream death effector proteins in order to kill cancer cells [26]. Using The Cancer Genome Atlas (TCGA) gene dataset (CGAN, 2012), we compared the expression of genes involved in cell death pathways between $\mathrm{ER}^{+}$and TNBCs. Interestingly, genes linked to the gene ontology (GO) term 'programmed cell death' ('PCD') were generally found to be expressed at higher levels in TNBC versus $\mathrm{ER}^{+}$samples (FRY gene set test $p=0.0005$ ). As the 'PCD' GO does not solely include genes that are involved in cell death induced by Smac mimetics, we refined our analysis to a subset of genes that we considered more likely to contribute to Smac-mimetic killing (Fig. 4a, b). Using this refined 'Smac-mimetic' signature, most genes encoding death receptor family members were strongly upregulated in patients with TNBC compared with those with $\mathrm{ER}^{+}$cancer (Fig. 3c and Supplementary Fig. 3). Significance for overall upregulation is $p=5.6 \mathrm{e}-06$ compared with all PCD genes despite the smaller gene set size. Interestingly, RIPKI and other genes encoding components of complex II (or Ripoptosome) were found to be downregulated in TNBC (Fig. 4c).

Given that treatment with birinapant removed differences in IAP levels between TNBC and $\mathrm{ER}^{+}$tumors (Fig. 3b), we postulated that differential levels of TNF and TNFR1 could account for $\mathrm{ER}^{+}$resistance and TNBC sensitivity to Smac mimetics. Consistent with this notion, transcripts encoding members of the death receptor family such as TNF (TNF), TNFR1 (TNFRSF1), FAS (FAS), or TRAIL-R2 (TNFRSF10B) were significantly higher in the TCGA TNBCs compared with $\mathrm{ER}^{+}$tumors (Fig. 4c, d). This differential expression was also observed in an independent dataset (METABRIC) covering 2000 breast cancers [31] as well as in our cohort of 10 PDX tumors (Fig. 4d). Furthermore, a neutralizing TNF antibody blocked Smacmimetic killing of TNBC PDXs, while addition of exogenous TNF further sensitized TNBC cells to birinapant (Figs. 1d, 4e, f). In contrast, addition of TNF did not increase complex II formation in $\mathrm{ER}^{+}$cells (Supplementary Fig. 4), nor enhance birinapant-mediated killing in $\mathrm{ER}^{+}$cell lines or the PDX-315 ER ${ }^{+}$model, although TNF slightly increases birinapant-mediated killing in PDX-23 (Fig. 4e, f). These results suggest that the basal levels of TNFR1 in $\mathrm{ER}^{+}$ tumors are generally not high enough for Smac mimetics to initiate cell death. 
2772

N. Lalaoui et al.

Fig. 2 In vive efficacy of birinapant in PDX models. a-e Tumor volume curves (left panels) and Kaplan-Meier survival curves (right panels) for the indicated PDX model $(n=6$ to 10 mice per arm). Mice were treated with vehicle alone (black lines) or $30 \mathrm{mg} / \mathrm{kg}$ of birinapant (red lines) intraperitoneally three times/week. The treatment time is represented by the gray bars on top of the tumor volume curves. Mice were sacrificed when tumor size reached the experimental ethical end point $\left(>600 \mathrm{~mm}^{3}\right)$. For tumor volume curves, means \pm SEM are shown.
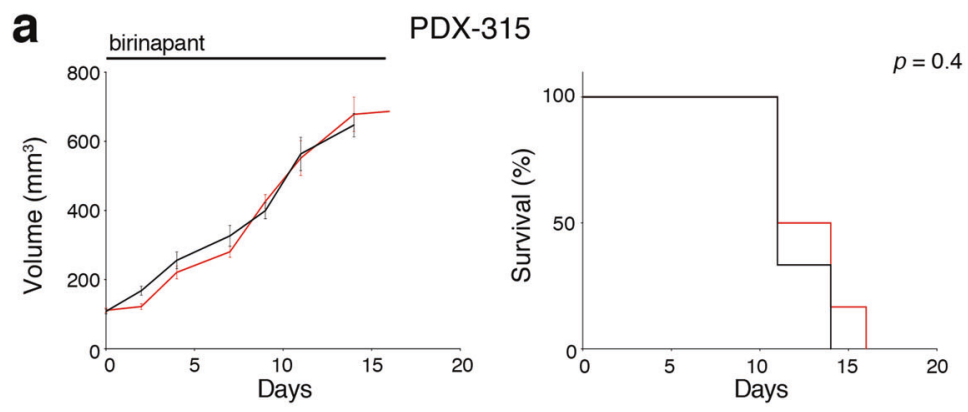

- vehicle

- birinapant

b birinapant $\quad$ PDX-23
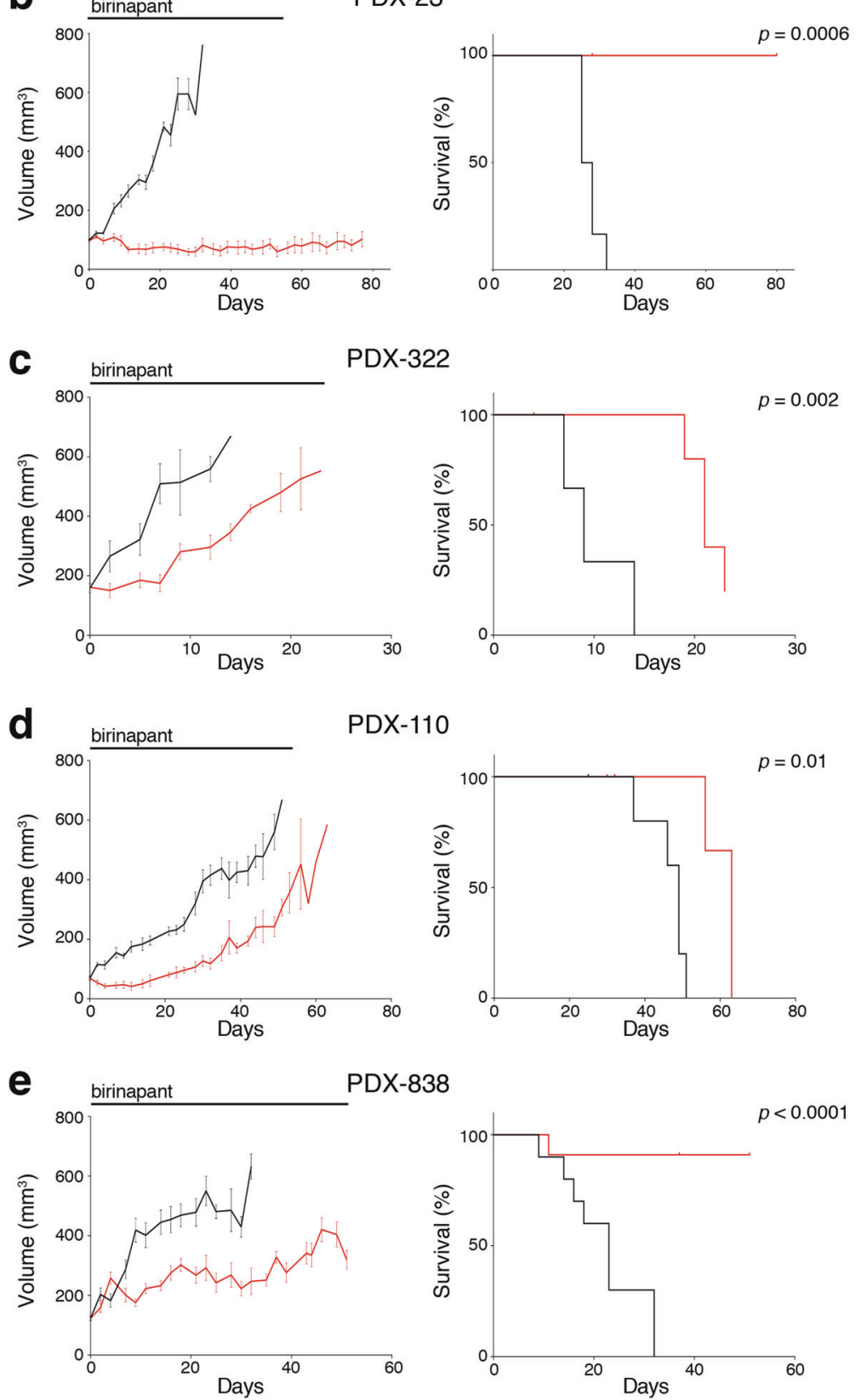

SPRINGER NATURE 
a

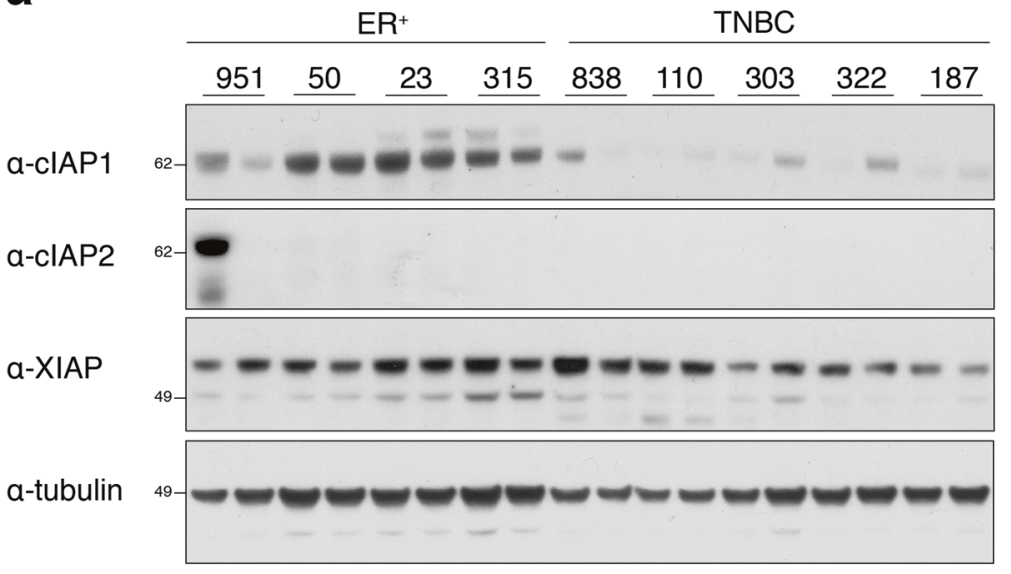

b

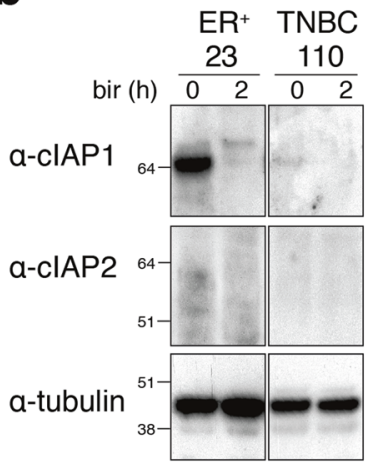

C

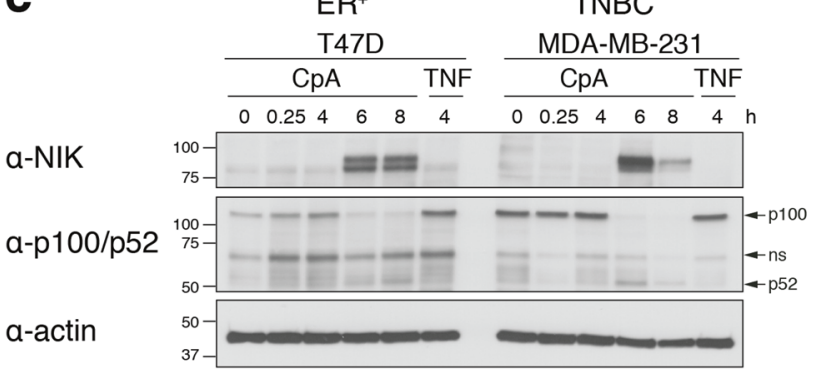

e

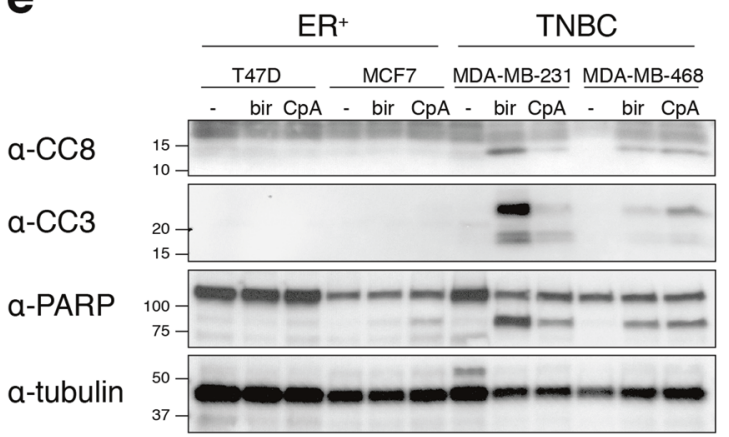

Fig. 3 Differential expression of cIAP1/2 in $\mathbf{E R}^{+}$and TNBC tumors. a Western blot analysis of cIAP1, cIAP2, and XIAP protein expression in the indicated $\mathrm{ER}^{+}$and TNBC PDX models. For each PDX, two lysates from independent mice are represented. b Western blot analysis of cIAP1 and cIAP2 protein expression in lysates from $\mathrm{ER}^{+}$PDX-23 and TNBC PDX-110 cell suspensions treated with $1 \mu \mathrm{M}$ of birinapant for $2 \mathrm{~h}$. $\mathbf{c}$ Western blot analysis of NIK, p100/p52 protein expression in indicated breast cancer cell lines treated at indicated times with $1 \mu \mathrm{M}$ of CompA (CpA) or with $100 \mathrm{ng} / \mathrm{ml}$ of TNF. d Levels

\section{Birinapant sensitizes TNBC PDX tumors to taxane therapy in vivo}

Although birinapant was effective as a single agent in TNBC PDX models in vivo, combination therapy could

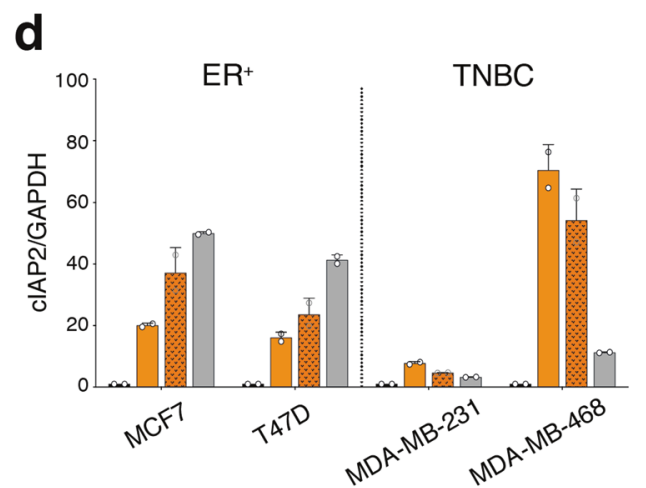

DMSO $\square \mathrm{CpA}(24 \mathrm{~h})$ 图 CpA (48 h) $\square \operatorname{TNF}(24$ h) of cIAP2 transcripts relative to GAPDH transcripts in indicated breast cancer cell lines treated with $1 \mu \mathrm{M}$ of CompA $(\mathrm{CpA})$ for $24 \mathrm{~h}$ or $48 \mathrm{~h}$ or with $100 \mathrm{ng} / \mathrm{ml}$ of TNF for $24 \mathrm{~h}$. The caspase inhibitor IDN-6556 $(5 \mu \mathrm{M})$ was added in all conditions to inhibit cell death. Bars represent mean \pm SD of duplicates of one representative experiment. e Western blot analysis of cleaved caspase-3 (CC3), cleaved caspase-8 (CC8) and PARP in lysates from indicated breast cancer cell lines treated with $1 \mu \mathrm{M}$ of birinapant (bir) or CompA $(\mathrm{CpA})$ for $24 \mathrm{~h}$. Tubulin $(\mathbf{a}, \mathbf{b})$ and actin (c, e) were used as loading controls. prove more potent. We therefore tested the ability of birinapant to sensitize TNBCs to the taxane docetaxel, which is widely used in breast cancer therapy. Birinapant enhanced killing by docetaxel in MDA-MB-231 cells in vitro (Fig. 5a). We next determined the therapeutic effect 


\section{a}

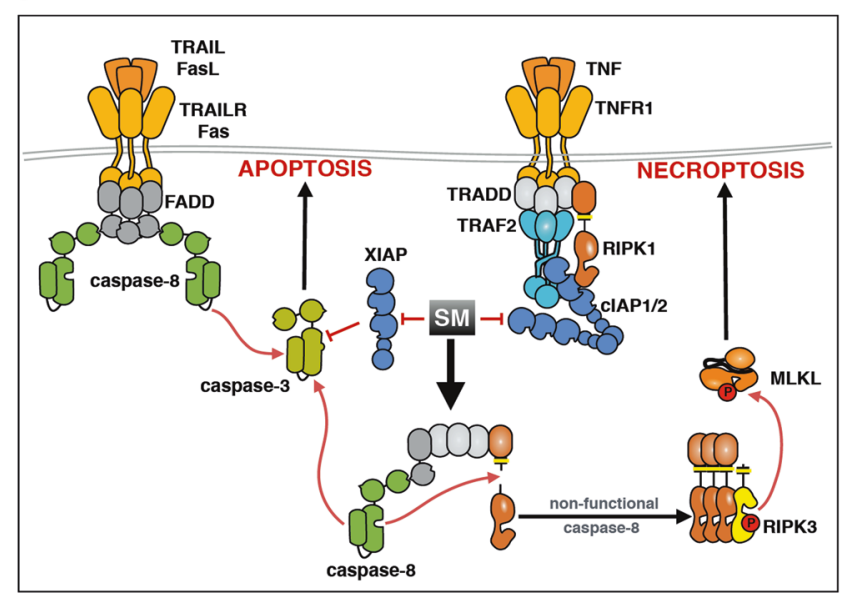

b

\begin{tabular}{l|l}
\multicolumn{1}{c|}{ Gene } & \multicolumn{1}{|c}{ Protein } \\
\hline TNF & TNF \\
TNFRSF1A & TNFR1 \\
TNFRSF1B & TNFR2 \\
TNFRSF10 & TRAIL \\
TNFRSF10A & TRAILR1 \\
TNFRSF10B & TRAILR2 \\
FASLG & FasL \\
FAS & Fas \\
FADD & FADD \\
TRADD & TRADD \\
TRAF2 & TRAF2 \\
CASP8 & Caspase-8 \\
CASP3 & Caspase-3 \\
RIPK1 & RIPK1 \\
$R I P K 3$ & RIPK3 \\
MLKL & MLKL \\
&
\end{tabular}

C

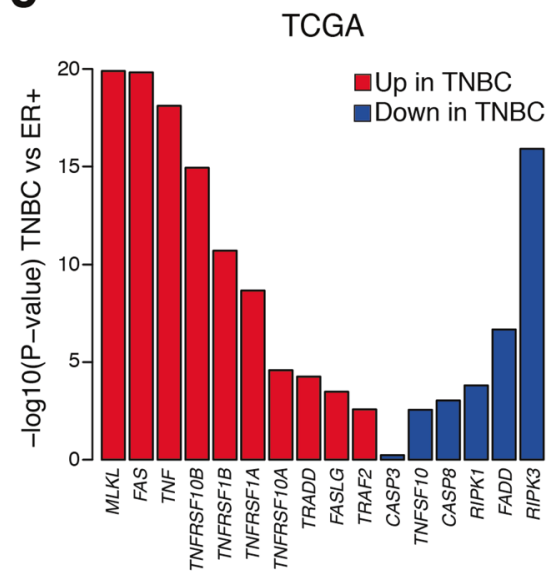

d

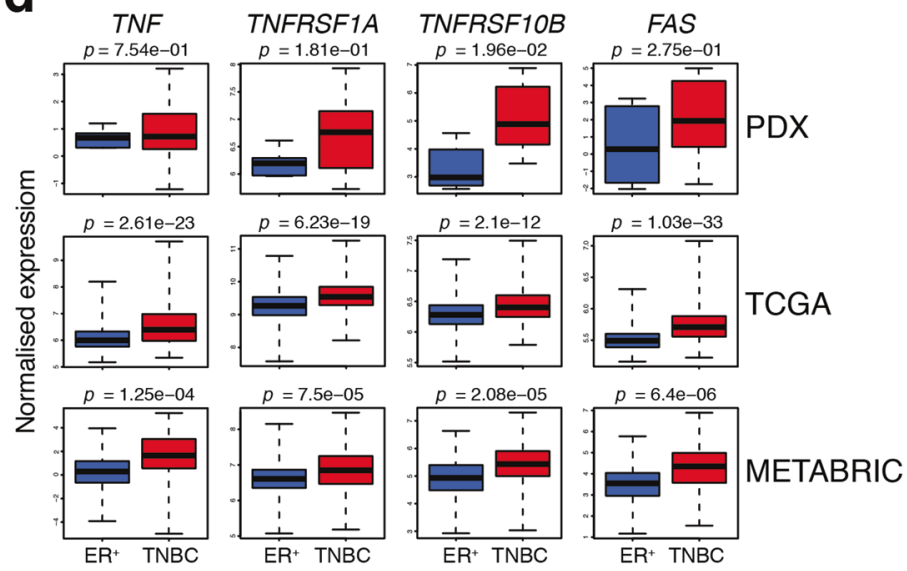

e

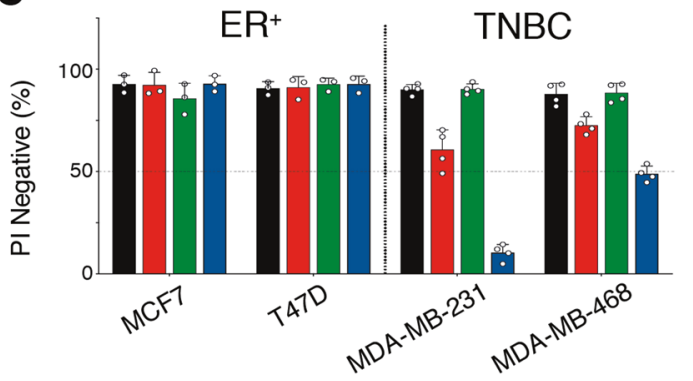

DDSO $\square$ birinapant $\square$ TNF 100 TTNF 100 + birinapant

Fig. 4 A gene expression profile that correlates with Smac-mimetic killing of TNBC. a Schematic of death receptor cell death signaling pathway. Effect of Smac-mimetic (SM)-induced inhibition of IAPs (red inhibitory arrows) and -induced formation of cell death complex (black arrow) are shown. b List of selected genes and their protein names that influence Smac-mimetic-induced cell death. c Most Smac-mimetic killing genes are upregulated in TCGA TNBC samples compared with $\mathrm{ER}^{+}$cancers $\left(n=132\right.$ for $\mathrm{ER}^{+}$and $n=183$ for TNBC, $\left.p=0.0005\right)$ but a minority are downregulated. The plot shows $-\log 10 p$ value and the direction of change for each gene in TNBC versus $\mathrm{ER}^{+}$samples. $\mathbf{d}$ Box plots representing the expression of indicated genes in PDX models (top panels, $n=3$ for $\mathrm{ER}^{+}$and $n=7$ for TNBC PDX models), in f

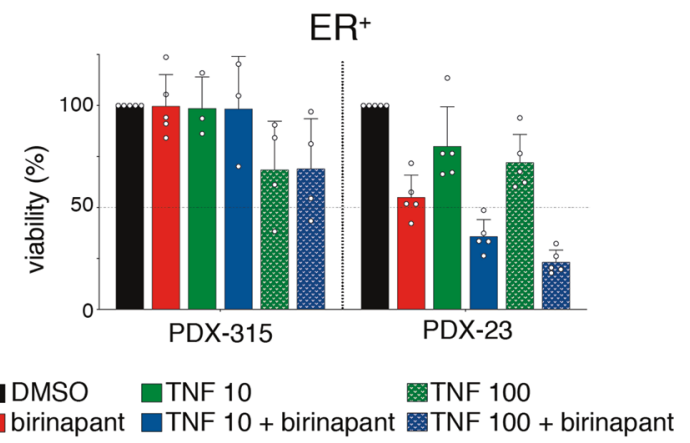

TCGA samples (middle panels, $n=132$ for $\mathrm{ER}^{+}$and $n=183$ for TNBC samples) and in METABRIC samples (bottom panels, $n=492$ for $\mathrm{ER}^{+}$and $n=331$ for TNBC samples). e Cell viability assessed by measurement of PI negative cells by flow cytometry of indicated breast cancer cell lines treated for $24 \mathrm{~h}$ with $1 \mu \mathrm{M}$ of birinapant or $100 \mathrm{ng} / \mathrm{ml}$ of TNF or combination of both. Data are means $\pm \mathrm{SD} ; n=2-3$ independent experiments. f Cell viability assessed using CellTiter-Glo of $\mathrm{ER}^{+} \mathrm{PDX}$ tumor cells treated for $24 \mathrm{~h}$ with $1 \mu \mathrm{M}$ of birinapant or $10 \mathrm{ng} /$ $\mathrm{ml}$ or $100 \mathrm{ng} / \mathrm{ml}$ of TNF (indicated as TNF 10 or TNF 100, respectively) or combination of birinapant with either TNF concentrations. Data are means $\pm \mathrm{SD} ; n=3-5$ independent tumors. e, f Each dot represents either an independent tumor or an independent experiment. 
a

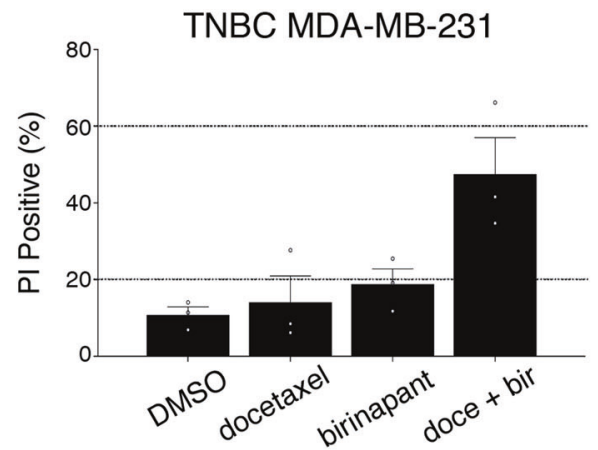

b
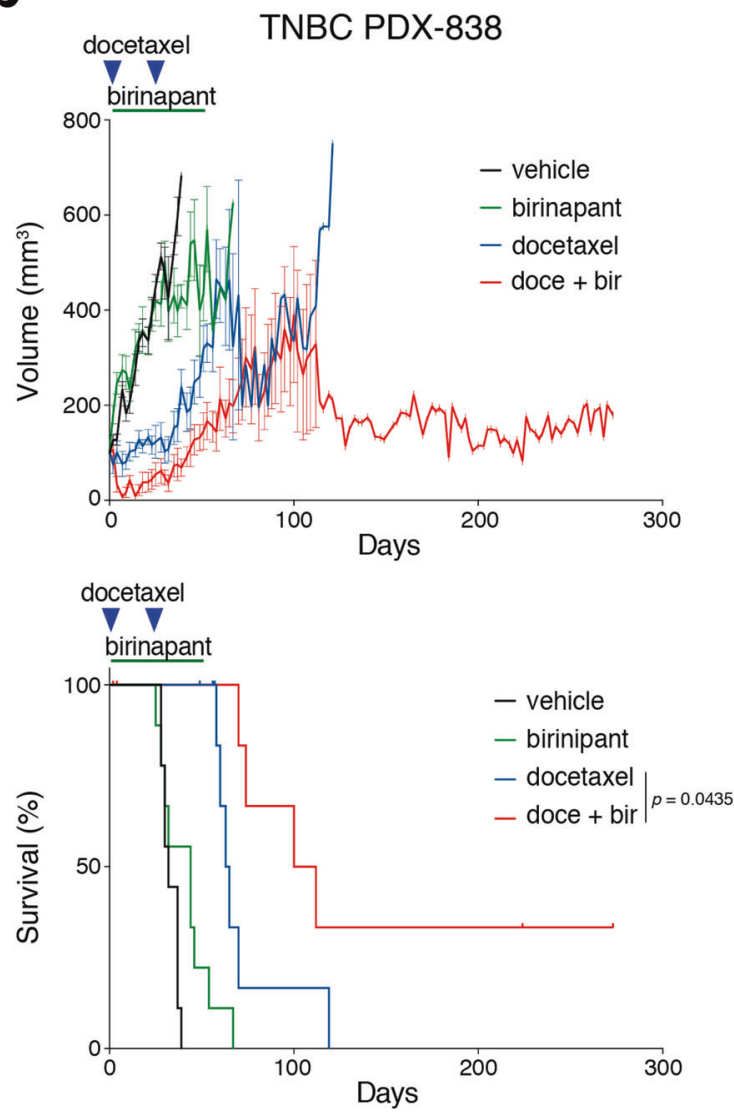

Fig. 5 Birinapant sensitizes TNBC PDX tumors to conventional therapy in vivo. a Cell death assessed by measurement of PI positive cells by flow cytometry of MDA-MD-231 cells treated with either $5 \mathrm{nM}$ of docetaxel for $48 \mathrm{~h}$ or $250 \mathrm{nM}$ of birinapant for $24 \mathrm{~h}$ or pretreated $24 \mathrm{~h}$ with $5 \mathrm{nM}$ of docetaxel and then treated $24 \mathrm{~h}$ with $250 \mathrm{nM}$ birinapant (doce + bir). Data are means $\pm \mathrm{SEM} ; n=3$ independent experiments. b Tumor volume curves (top panels) and Kaplan-Meier survival curves (bottom panels) for TNBC PDX-838 $(n=6-9$ mice per arm). Mice were treated with vehicle alone (black line) or $15 \mathrm{mg} /$ $\mathrm{kg}$ of birinapant alone (green line, intraperitoneally three times/week for seven weeks) or with $10 \mathrm{mg} / \mathrm{kg}$ docetaxel alone (blue line, intraperitoneally on days 1 and 22) or with combined docetaxel and birinapant (red line). Mice were sacrificed when tumor size reached the experimental ethical end point $\left(>600 \mathrm{~mm}^{3}\right)$. For tumor volume curves, means \pm SEM are shown. c Immunostaining for cleaved caspase- 3
C

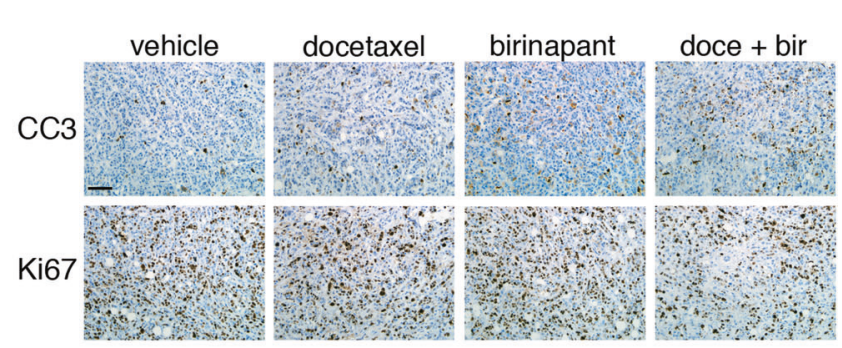

\section{TNBC PDX-838}

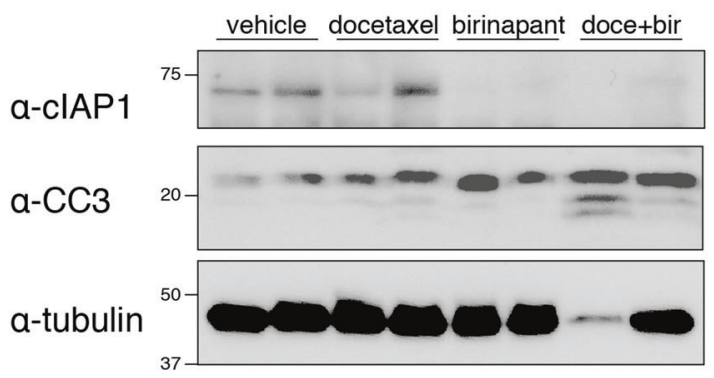

e
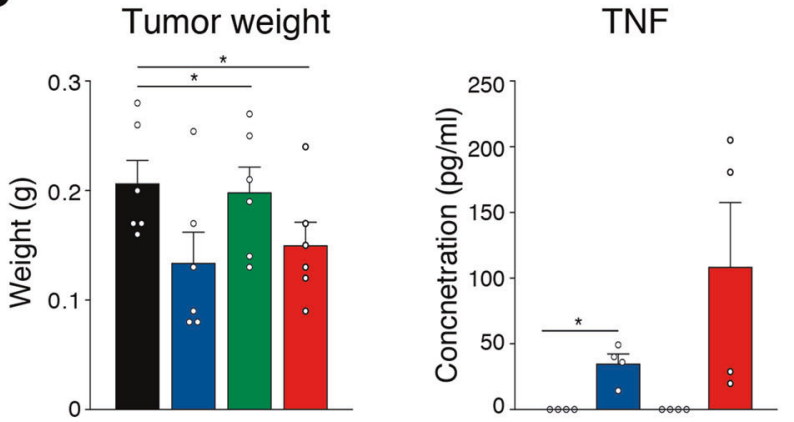

vehicle $\square$ docetaxel $\square$ birinapant $\square$ doce + bir

(CC3) and Ki67 of PDX-838 tumors treated in vivo with vehicle or with $15 \mathrm{mg} / \mathrm{kg}$ of birinapant or with $10 \mathrm{mg} / \mathrm{kg}$ docetaxel or with combined docetaxel and birinapant for $24 \mathrm{~h}$. Scale bar, $50 \mu \mathrm{m}$. d Western blot analysis of cIAP1 and cleaved caspase- 3 protein expression in lysates from PDX 838 tumors treated in vivo with vehicle or with $15 \mathrm{mg} / \mathrm{kg}$ of birinapant or with $10 \mathrm{mg} / \mathrm{kg}$ docetaxel or with combined docetaxel and birinapant for $24 \mathrm{~h}$ (two independent tumors per treatment). e Tumor weights from PDX 838 tumors treated in vivo with vehicle or with $15 \mathrm{mg} / \mathrm{kg}$ of birinapant or with $10 \mathrm{mg} / \mathrm{kg}$ docetaxel or with combined docetaxel and birinapant for $24 \mathrm{~h}$ (left panel). Level of TNF measured by ELISA in lysate from PDX838 tumors treated in vivo with vehicle or $15 \mathrm{mg} / \mathrm{kg}$ of birinapant or with $10 \mathrm{mg} / \mathrm{kg}$ docetaxel or with combined docetaxel and birinapant for $24 \mathrm{~h}$ (right panel). Data are means $\pm \mathrm{SD} ; n=4-6$ independent tumors. Each dot represents an independent tumor. 
of this combination in the PDX-838 model of TNBC in vivo. Mice were treated with docetaxel $(10 \mathrm{mg} / \mathrm{kg}$ i.p. $)$ every 21 days for two cycles with or without birinapant (15 $\mathrm{mg} / \mathrm{kg}$ i.p.) administered three times a week for seven weeks (Fig. 5b and Supplementary Fig. 5). At this dose, birinapant alone was insufficient to inhibit tumor growth. When combined with docetaxel, however, tumor growth was significantly curtailed, accompanied by a significant improvement in animal survival (median survival 66 days versus 106 days; $p<0.05$ ) (Fig. 5b). As expected, combined therapy increased apoptosis and reduced tumor cell proliferation, as determined by immunostaining for cleaved caspase-3 (CC3) and Ki67 (Fig. 5c) and Western blot analysis of $\mathrm{CC} 3$ (Fig. 5d). It has been reported that docetaxel can stimulate TNF production in breast cancer cells $[32,33]$. To determine whether TNF induced by docetaxel synergized with birinapant, we measured TNF levels in tumor lysates and in the serum of treated mice. Docetaxel or docetaxel plus birinapant significantly reduced tumor weight at $24 \mathrm{~h}$ (Fig. 5e, left panel), accompanied by an increase in TNF expression by docetaxel and further elevation by its combination with birinapant (Fig. 5e, right panel). These findings are consistent with docetaxel sensitizing TNBC to birinapant via the induction of TNF.

\section{Discussion}

There remain few targeted therapies available for patients with TNBC, underscoring the importance of identifying new targets. In this study, we have explored the IAP inhibitor birinapant as a possible targeting strategy and found that single agent therapy produces a therapeutic response in TNBC PDX models. Our findings shed light on possible preferential activity of Smac mimetics in TNBC, which is consistent with the elevated expression of genes encoding mediators that could influence Smac-mimetic killing in TNBC compared with $\mathrm{ER}^{+}$breast cancer. This is in keeping with a recent description of a $\mathrm{TNF} \alpha$ gene expression signature that is enriched in TNBC [20].

The high level of cIAP1 in $\mathrm{ER}^{+} \mathrm{PDX}$ and their resistance to Smac-mimetic-induced cell death appears counterintuitive. Indeed, our assumption had been that cells with the highest levels of IAPs would be the most addicted to IAPs and the most sensitive to inhibition. However, despite rapid cIAP1 degradation and higher gene expression of the main components of complex II, Smac mimetics failed to efficiently activate caspases and kill $\mathrm{ER}^{+}$tumors. We previously showed that $\mathrm{ER}^{+}$tumors undergo apoptosis following BCL-2 inhibition [34], demonstrating that the executioner caspases are functional in this breast cancer subtype. Taken together, our findings suggest that most $\mathrm{ER}^{+}$ tumors, in contrast to TNBC, are deficient in their ability to form and/or activate complex II. Recent reports showed that complex II activity can be limited by the kinases IKK $\alpha, \beta, \varepsilon$, p38, MK2, TBK1, or by the E3 ligase MIB2 [35-42]. These proteins restrain the cytotoxic activity of RIPK1 upon Smacmimetic treatment $[35,36]$. Interestingly, the level of IKK $\alpha / \beta$ transcripts was significantly lower in TNBC compared with $\mathrm{ER}^{+}$tumors in TCGA samples, which may in part account for the ability of TNBC cells to activate the cytotoxic activity of RIPK1 (Supplementary Fig. 6). In contrast, while MIB2 expression shows an opposite trend and is elevated in TNBC relative to $\mathrm{ER}^{+}$cancers, we did not find differences in the expression of MAPK14 (p38) or MAPKAP2 (MK2) between TCGA ER ${ }^{+}$and TNBC samples (Supplementary Fig. 6). Because RNA transcript levels do not always predict protein activity, it will be interesting to further explore the role of these 'RIPK1 blockers' in $\mathrm{ER}^{+}$breast cancers.

For most Smac mimetics, the level of cIAPs and their degradation upon treatment are readily ascertainable biomarkers of drug-target engagement and drug response $[43,44]$. Although cancers may select for high levels of IAPs $[45,46]$, our data suggest that screening for IAP levels and degradation may not predict responsiveness. One feature of Smac mimetics is that they have a two-pronged mechanism of action: they induce TNF and simultaneously sensitize cells to this ligand. Thus, if cancer cells fail to produce TNF upon Smac-mimetic treatment, exogenous TNF would sensitize them to Smac mimetics only if they express TNFR1. Consistent with this, treatment with birinapant and high concentrations of exogenous TNF did not sensitize $\mathrm{ER}^{+}$cancer cells, presumably reflecting their low levels of TNFR1.

The efficacy of Smac mimetics relies on sufficient quantities of TNF, which can be augmented by other means, including innate immune stimuli [47-49], p38, MK2, or caspase inhibitors [37, 50]. Although high levels of TNF can be a concern in regard to safety, these combinations have been proven to be well-tolerated in mice [37, 47, 49, 50]. The combination of birinapant and docetaxel may also offer a dual mechanism of action to achieve clinical benefit as both agents augment TNF production. The safety of the combination of the Smac-mimetic LCL161 with a taxane has been evaluated in the clinic (NCT01188499). Cytokine release syndrome (CRS) appeared to be a dose limiting toxicity for patients treated with both LCL161 and paclitaxel [20]. Importantly, this adverse event has so far not been reported in patients treated with birinapant alone or when combined with docetaxel (NCT01188499). The highly inflammatory cytokine IL-1 $\beta$ can be released when all IAPs are inhibited [51-55]. Consistent with this idea and due to its ability to efficiently target all IAPs, LCL161 can induce the release of IL-1 $\beta$ in different cell types, while birinapant cannot $[23,52]$. Therefore, it is plausible that release of IL- $1 \beta$ participated in the CRS observed in patients treated with LCL161. Conversely, cytokine induction by Smac mimetics could enhance 
an anti-tumor immune response [56-58], and combinations with immune checkpoint inhibitors may be worth investigating given recent findings with nab-paclitaxel and the PDL1 inhibitor atezolizumab in PD-L1 positive TNBC [9].

Our findings are in line with a recently published study that identified a predictive gene signature enriched in TNBC, which also included TNF [20]. Our Smac-mimetic gene set revealed increased $T N F$ levels but also showed elevated expression of genes encoding death receptors and their ligands in TNBC. These factors, if absent or expressed at low levels, would significantly limit Smac-mimetic efficacy. Collectively, our data suggest that the Smac-mimetic gene set may serve as a predictive biomarker to stratify patients for Smac-mimetic-based therapies and support additional early-phase clinical evaluations of birinapant combined with docetaxel in TNBC patients.

\section{Materials and methods}

\section{Reagents and antibodies}

Birinapant, CompA, necrostatin, and IDN- $6556^{50}$ were gifts from TetraLogic Pharmaceuticals. Fc-TNF was generated inhouse. Q-VD-OPh (Q-VD) was purchased from MP Biomedicals. Docetaxel was purchased from ActiveBiochem. Antibodies used for neutralization assays anti-TNF (MAB610) and anti-TRAIL (MAB375) were purchased from R\&D Systems. Antibodies used for immunoblotting and immunohistochemistry were purchased as follows: anticIAP1 (1E1-1-10) and anti-cIAP2 (16E-6-3) from Enzo, antiXIAP (2F1) from MBL, anti-cleaved caspase-3 (Asp175) from Cell Signaling Technology), anti-NIK (Cell Signaling Technology), anti-p100/p52 (Cell Signaling Technology), anti-tubulin (DM1A) and anti-actin (AC-15) from SigmaAldrich, and anti-KI67 (Thermo Fisher Scientific).

\section{Viability assays}

The breast cancer cell lines MCF-7, T47D, MDA-MB-231, and MDA-MB-468 were maintained in RPMI-1640 (Gibco) supplemented with $10 \%$ fetal calf serum (FCS) and were mycoplasma free. For viability assays, breast cancer cell lines were plated at $5 \times 10^{4}$ cells/well in 48 well plates and treated with indicated reagents. Propidium iodide exclusion $(5 \mu \mathrm{g} / \mathrm{ml})$ was analyzed by flow cytometry. For tumor sphere assays, single cell suspensions were obtained by digestion of primary tumors, sorted and cultured in mammosphere medium as previously described [34]. $3 \times 10^{4}$ cells/well were plated in 96 well plates and treated with indicated reagents. Cell viability was assessed using the CellTiter-Glo Luminescent Assay (Promega) as per the manufacturer's instructions.

\section{In vivo experiments}

Human breast cancer tissues were obtained from consenting patients through the Royal Melbourne Hospital Tissue Bank and the Victorian Cancer Biobank with relevant institutional review board approval and were used to derive the PDX models (characterized in [22, 34, 59]). Human ethics approval was obtained from the Walter and Eliza Hall Institute (WEHI) Human Research Ethics Committee. Animal experiments were approved by the WEHI Animal Ethics Committee. Cohorts of NOD-SCID-IL $2 \mathrm{R} \gamma^{-1-}$ female mice were seeded with thawed single cell suspensions of early passage human breast tumors (passage 2 or 3 ). Briefly, $150,000-250,000$ cells were resuspended in $10 \mu \mathrm{l}$ of transplantation buffer (50\% FCS, $10 \%$ of a $0.04 \%$ trypan blue solution, and 40\% PBS) and growth factor-reduced Matrigel [BD] at a ratio of 3:1, and injected into the cleared mammary fat pads of 3-4 weeks old NOD-SCID-IL $2 \mathrm{R} \gamma_{\mathrm{c}}{ }^{-1-}$ female mice. Mice were monitored for tumor development three times weekly and tumor size measured using electronic vernier calipers. Tumor volume was estimated by measuring the minimum and maximum tumor diameters using the formula: (minimum diameter) ${ }^{2}$ (maximum diameter)/2. Once tumors reached a volume of $80-120 \mathrm{~mm}^{3}$, mice were randomized into treatment arms and treatment commenced. As power analysis was not possible in the absence of prior knowledge on the drug effect, we used the equation as described in http://www.3rs-reduction.co.uk/ $\mathrm{html} / 6$ __power_and_sample_size.html. Based on the equation, all experiments described have an $E$ value equal or superior to 10. Randomization and tumor measurements were managed using the Study Director software (v 3.0, studylog). Mice were sacrificed at the first measurement where tumor volume exceeded $600 \mathrm{~mm}^{3}$, or if their health deteriorated for reasons other than disease progression or drug toxicity (censored event). Although $>10 \%$ weight loss was a predefined censoring event, no mice in the treatment cohorts lost weight. Animal technicians and researchers blinded to treatment conditions measured the tumors volume and euthanized the mice on ethical grounds. For single agent treatments vehicle for birinapant ( $6 \%$ captisol) or birinapant $(30 \mathrm{mg} / \mathrm{kg})$ were injected i.p. three times weekly continuously. For combination treatments vehicle (6\% captisol) or birinapant $(30 \mathrm{mg} / \mathrm{kg}$ ) were injected i.p. three times weekly for seven weeks. Docetaxel $(10 \mathrm{mg} / \mathrm{kg})$ was injected i.p. every 21 days for two treatment cycles. For the analysis of CC3, Ki67, and TNF, mice were treated with either vehicle (6\% captisol) or birinapant $(30 \mathrm{mg} / \mathrm{kg})$ or docetaxel $(10 \mathrm{mg} / \mathrm{kg})$ or combined birinapant and docetaxel. After $24 \mathrm{~h}$ of treatment, tumors were collected and sectioned in two pieces. One was used for immunohistochemistry (detail see below) and the other for TNF measurement. For the TNF ELISA, tumors were lysed in RIPA buffer $(20 \mathrm{mM}$ 
Tris- $\mathrm{HCl} \mathrm{pH}$ 7.5, $135 \mathrm{mM} \mathrm{NaCl}, 1.5 \mathrm{mM} \mathrm{MgCl}, 1 \mathrm{mM}$ EGTA, $1 \%$ Triton X-100, and 10\% glycerol). Protein lysates were analyzed by ELISA following the manufacturer's instructions (eBioscience).

\section{Immunoblot analysis}

Tumors were lysed in RIPA buffer $(20 \mathrm{mM}$ Tris- $\mathrm{HCl} \mathrm{pH}$ $7.5,135 \mathrm{mM} \mathrm{NaCl}, 1.5 \mathrm{mMMgCl}_{2}, 1 \mathrm{mM}$ EGTA, $1 \%$ Triton $\mathrm{X}-100$, and $10 \%$ glycerol). Protein lysates were analyzed by Western blot on 4-15\% SDS-polyacrylamide gels (BioRad), transferred onto PVDF membranes (Millipore), and probed with indicated primary antibodies. After primary antibody, membranes were probed using HRPconjugated anti-IgG secondary antibodies and ECL (GE Healthcare Life Sciences).

\section{Immunohistochemistry}

PDX tumors were collected and fixed in $10 \%$ neutral buffered formalin before embedding in paraffin. Sections were dewaxed and subjected to heat-induced epitope retrieval with boiling citrate buffer, then blocked and permeabilized with $1 \%$ bovine serum albumin and $0.3 \%$ Triton X-100. Immunohistochemistry sections were stained with anti-CC3 (Cell Signaling Technology) or anti-Ki67 (Thermo Fisher Scientific) at $4{ }^{\circ} \mathrm{C}$ overnight and followed by anti-rabbit secondary (Agilent Technologies). Signal detection was performed using ABC Elite (Vector Labs) for $30 \mathrm{~min}$ and 3,3'-diaminobenzidine (Dako) for $5 \mathrm{~min}$ at room temperature.

\section{RNA-seq analysis of PDX tumors}

RNA from PDX tumors was sequenced on a HiSeq 2000 at the Australian Genome Research Facility, Melbourne. Xenografts were derived from three $\mathrm{ER}^{+}$and seven TNBC patients, and each tumor was passaged in $2-4$ mice. An average of 20 million $100 \mathrm{bp}$ paired-end reads were obtained per sample. Reads were aligned to the human genome hg19 using Rsubread package 1.16.1 [60] and were assigned to Entrez genes using featureCounts [61]. Library sizes were normalized by Trimmed Median of $M$-values [62] and converted to $\log 2$ counts per million ( $\log \mathrm{CPM})$ using the edgeR package.

\section{Publicly available breast cancer datasets}

RSEM counts for the TCGA breast cancer tumors were downloaded from https://tcga-data.nci.nih.gov and converted to $\log C P M$ values using edgeR. Differential expression between TNBC and $\mathrm{ER}^{+}$tumors was assessed using the limma software package [63] and the voom method [64]. Gene set tests were conducted using the FRY method [65] to determine whether the average logexpression of all genes in the set is changed between tumor types. Normalized microarray expression data from the METABRIC project [31] were downloaded from http://www.compbio.group.cam.ac.uk/publications/ supplementary-material.

\section{Statistical analysis}

Unless otherwise specified, data are presented as mean \pm SD. For tumor weight and TNF ELISA comparisons were performed with a Student's $t$ test and for Kaplan-Meier survival curves comparisons were performed with a logrank (Mantel-Cox) test. All $p$ values are denoted in the figures.

Acknowledgements We thank former employees of TetraLogic Pharmaceuticals for support and discussions, in particular Stephen Condon, C. Glenn Begley, Mark McKinlay, Sri Chunduri, and Chris Benetatos. We thank Kevin Liu for animal care. Coded breast tumor samples were provided by the Victorian Cancer Biobank (supported by the Victorian Government). NL was supported by the Worldwide Cancer Research grant 15-0042, by a Victoria Cancer Agency MidCareer Fellowship \#17030 and by the Cancer Australia and Cure Cancer foundation Project Grant \#1145588. DM was supported by the National Breast Cancer Foundation. GKS is supported by an NHMRC Research Fellowship \#1058892. DLV is supported by an NHMRC Research Fellowship \#1020136 and the Leukemia and Lymphoma Society SCOR grant \#7001-13. JEV is supported by an NHMRC Research Fellowship \#1037230. GJL is supported by an NHMRC Fellowship \#1078730. JS is supported by an NHMRC Research Fellowship \#1107149. This work was funded by NHMRC grants \#1054618, \#1025594, \#1046984, \#1016701, \#1101378 and \#1113133, and made possible through Victorian State Government Operational Infrastructure Support and Australian Government NHMRC IRIISS (9000433).

\section{Compliance with ethical standards}

Conflict of interest DLV and JS were on the Scientific advisory board of TetraLogic Pharmaceuticals until 2016.

Publisher's note Springer Nature remains neutral with regard to jurisdictional claims in published maps and institutional affiliations.

Open Access This article is licensed under a Creative Commons Attribution 4.0 International License, which permits use, sharing, adaptation, distribution and reproduction in any medium or format, as long as you give appropriate credit to the original author(s) and the source, provide a link to the Creative Commons license, and indicate if changes were made. The images or other third party material in this article are included in the article's Creative Commons license, unless indicated otherwise in a credit line to the material. If material is not included in the article's Creative Commons license and your intended use is not permitted by statutory regulation or exceeds the permitted use, you will need to obtain permission directly from the copyright holder. To view a copy of this license, visit http://creativecommons. org/licenses/by/4.0/. 


\section{References}

1. Perou CM, Sorlie T, Eisen MB, van de Rijn M, Jeffrey SS, Rees $\mathrm{CA}$, et al. Molecular portraits of human breast tumours. Nature. 2000;406:747-52.

2. Teschendorff AE, Miremadi A, Pinder SE, Ellis IO, Caldas C. An immune response gene expression module identifies a good prognosis subtype in estrogen receptor negative breast cancer. Genome Biol. 2007;8:R157.

3. Sorlie T, Perou CM, Tibshirani R, Aas T, Geisler S, Johnsen H, et al. Gene expression patterns of breast carcinomas distinguish tumor subclasses with clinical implications. Proc Natl Acad Sci USA. 2001;98:10869-74.

4. Cancer Genome Atlas Network. Comprehensive molecular portraits of human breast tumours. Nature. 2012;490:61-70.

5. Lakhani SR, Ellis IO, Schnitt SJ, Tan PH, van de Vijver MJ. WHO classification of tumours of the breast. 4th edn. vol. 4 (WHO Press, Geneva, 2012).

6. Harris L, Fritsche H, Mennel R, Norton L, Ravdin P, Taube S, et al. American Society of Clinical Oncology 2007 update of recommendations for the use of tumor markers in breast cancer. $\mathrm{J}$ Clin Oncol. 2007;25:5287-312.

7. Early Breast Cancer Trialists' Collaborative Group. Tamoxifen for early breast cancer: an overview of the randomised trials. Early Breast Cancer Trialists' Collaborative Group. Lancet. 1998;351:1451-67.

8. Romond EH, Perez EA, Bryant J, Suman VJ, Geyer CE Jr, Davidson NE, et al. Trastuzumab plus adjuvant chemotherapy for operable HER2-positive breast cancer. $N$ Engl J Med. 2005;353:1673-84.

9. Schmid P, Adams S, Rugo HS, Schneeweiss A, Barrios CH, Iwata $\mathrm{H}$, et al. Atezolizumab and Nab-Paclitaxel in Advanced triplenegative breast cancer. N Engl J Med. 2018;379:2108-21.

10. Lalaoui N, Vaux, DL. Recent advances in understanding inhibitor of apoptosis (IAP) proteins. F1000 Research. 2018; https://doi. org/10.12688/f1000research.6439.1.

11. Fulda S. Smac mimetics to therapeutically target IAP proteins in cancer. Int Rev Cell Mol Biol. 2017;330:157-69.

12. Du C, Fang M, Li Y, Li L, Wang X. Smac, a mitochondrial protein that promotes cytochrome c-dependent caspase activation by eliminating IAP inhibition. Cell. 2000;102:33-42.

13. Verhagen AM, Ekert PG, Pakusch M, Silke J, Connolly LM, Reid GE, et al. Identification of DIABLO, a mammalian protein that promotes apoptosis by binding to and antagonizing IAP proteins. Cell. 2000;102:43-53.

14. Lalaoui N, Lindqvist LM, Sandow JJ, Ekert PG. The molecular relationships between apoptosis, autophagy and necroptosis. Semin Cell Dev Biol. 2015;39:63-9.

15. Varfolomeev E, Blankenship JW, Wayson SM, Fedorova AV, Kayagaki N, Garg P, et al. IAP antagonists induce autoubiquitination of c-IAPs, NF-kappaB activation, and TNFalphadependent apoptosis. Cell. 2007;131:669-81.

16. Petersen SL, Wang L, Yalcin-Chin A, Li L, Peyton M, Minna J, et al. Autocrine TNFalpha signaling renders human cancer cells susceptible to Smac-mimetic-induced apoptosis. Cancer Cell. 2007; 12:445-56.

17. Vince JE, Wong WW-L, Khan N, Feltham R, Chau D, Ahmed AU, et al. IAP antagonists target cIAP1 to induce TNFalphadependent apoptosis. Cell. 2007;131:682-93.

18. Srinivasula SM, Hegde R, Saleh A, Datta P, Shiozaki E, Chai J, et al. A conserved XIAP-interaction motif in caspase-9 and Smacl DIABLO regulates caspase activity and apoptosis. Nature. 2001;410:112-6.
19. Cong H, Xu L, Wu Y, Qu Z, Bian T, Zhang W, et al. Inhibitor of apoptosis protein (IAP) antagonists in anticancer agent discovery: current status and perspectives. J Med Chem. 2019;62:5750-577.

20. Bardia A, Parton M, Kummel S, Estevez LG, Huang CS, Cortes J, et al. Paclitaxel with inhibitor of apoptosis antagonist, LCL161, for localized triple-negative breast cancer, prospectively stratified by gene signature in a biomarker-driven neoadjuvant trial. J Clin Oncol. 2018;36:3126-33.

21. Nikkhoo A, Rostami N, Hojjat-Farsangi M, Azizi G, Yousefi B, Ghalamfarsa G, et al. Smac mimetics as novel promising modulators of apoptosis in the treatment of breast cancer. J Cell Biochem. 2019;120:9300-14.

22. Merino D, Whittle JR, Vaillant F, Serrano A, Gong JN, Giner G, et al. Synergistic action of the MCL-1 inhibitor S63845 with current therapies in preclinical models of triple-negative and HER2-amplified breast cancer. Sci Transl Med. 2017;9:eaam7049.

23. Condon SM, Mitsuuchi Y, Deng Y, LaPorte MG, Rippin SR, Haimowitz T, et al. Birinapant, a smac-mimetic with improved tolerability for the treatment of solid tumors and hematological malignancies. J Med Chem. 2014;57:3666-77.

24. Roesler S, Eckhardt I, Wolf S, Fulda S. Cooperative TRAIL production mediates IFNalpha/Smac mimetic-induced cell death in TNFalpha-resistant solid cancer cells. Oncotarget. 2016;7:3709-25.

25. Beug ST, LaCasse EC, Korneluk RG. Smac mimetics combined with innate immune stimuli create the perfect cytokine storm to kill tumor cells. Oncoimmunology. 2014;3:e28541.

26. Gaither A, Porter D, Yao Y, Borawski J, Yang G, Donovan J, et al. A Smac mimetic rescue screen reveals roles for inhibitor of apoptosis proteins in tumor necrosis factor-alpha signaling. Cancer Res. 2007;67:11493-8.

27. Silke J, Vucic D. IAP family of cell death and signaling regulators. Methods Enzymol. 2014;545:35-65.

28. Darding M, Feltham R, Tenev T, Bianchi K, Benetatos C, Silke J, et al. Molecular determinants of Smac mimetic induced degradation of cIAP1 and cIAP2. Cell Death Differ. 2011;18:1376-86.

29. Rothe M, Pan MG, Henzel WJ, Ayres TM, Goeddel DV. The TNFR2-TRAF signaling complex contains two novel proteins related to baculoviral inhibitor of apoptosis proteins. Cell. 1995;83:1243-52.

30. Vallabhapurapu S, Matsuzawa A, Zhang W, Tseng PH, Keats JJ, Wang $\mathrm{H}$, et al. Nonredundant and complementary functions of TRAF2 and TRAF3 in a ubiquitination cascade that activates NIK-dependent alternative NF-kappaB signaling. Nat Immunol. 2008;9:1364-70.

31. Curtis C, Shah SP, Chin SF, Turashvili G, Rueda OM, Dunning $\mathrm{MJ}$, et al. The genomic and transcriptomic architecture of 2,000 breast tumours reveals novel subgroups. Nature. 2012;486: 346-52.

32. Sprowl JA, Reed K, Armstrong SR, Lanner C, Guo B, Kalatskaya $\mathrm{I}$, et al. Alterations in tumor necrosis factor signaling pathways are associated with cytotoxicity and resistance to taxanes: a study in isogenic resistant tumor cells. Breast Cancer Res. 2012;14:R2.

33. Edwardson DW, Boudreau J, Mapletoft J, Lanner C, Kovala AT, Parissenti AM. Inflammatory cytokine production in tumor cells upon chemotherapy drug exposure or upon selection for drug resistance. PLoS One. 2017;12:e0183662.

34. Vaillant F, Merino D, Lee L, Breslin K, Pal B, Ritchie ME, et al. Targeting BCL-2 with the BH3 mimetic ABT-199 in estrogen receptor-positive breast cancer. Cancer Cell. 2013;24:120-9.

35. Jaco I, Annibaldi A, Lalaoui N, Wilson R, Tenev T, Laurien L, et al. MK2 phosphorylates RIPK1 to prevent TNF-induced cell death. Mol Cell. 2017;66:698-710. 
36. Feltham R, Jamal K, Tenev T, Liccardi G, Jaco I, Domingues CM, et al. Mind bomb regulates cell death during TNF Signaling by suppressing RIPK1's cytotoxic potential. Cell Rep. 2018;23: 470-84.

37. Lalaoui N, Hanggi K, Brumatti G, Chau D, Nguyen NY, Vasilikos $\mathrm{L}$, et al. Targeting p38 or MK2 enhances the anti-leukemic activity of Smac-mimetics. Cancer Cell. 2016;29:145-58.

38. Dondelinger Y, Delanghe T, Rojas-Rivera D, Priem D, Delvaeye T, Bruggeman I, et al. MK2 phosphorylation of RIPK1 regulates TNF-mediated cell death. Nat Cell Biol. 2017;19:1237-47.

39. Dondelinger Y, Jouan-Lanhouet S, Divert T, Theatre E, Bertin J, Gough PJ, et al. NF-kappaB-independent role of IKKalpha/IKKbeta in preventing RIPK1 kinase-dependent apoptotic and necroptotic cell death during TNF signaling. Mol Cell. 2015;60: 63-76.

40. Menon MB, Gropengiesser J, Fischer J, Novikova L, Deuretzbacher A, Lafera J, et al. p38(MAPK)/MK2-dependent phosphorylation controls cytotoxic RIPK1 signalling in inflammation and infection. Nat Cell Biol. 2017;19:1248-59.

41. Lafont E, Draber P, Rieser E, Reichert M, Kupka S, de Miguel D, et al. TBK1 and IKKepsilon prevent TNF-induced cell death by RIPK1 phosphorylation. Nat Cell Biol. 2018;20:1389-99.

42. Dondelinger Y, Delanghe T, Priem D, Wynosky-Dolfi MA, Sorobetea D, Rojas-Rivera D, et al. Serine 25 phosphorylation inhibits RIPK1 kinase-dependent cell death in models of infection and inflammation. Nat Commun. 2019;10:1729.

43. Amaravadi RK, Schilder RJ, Martin LP, Levin M, Graham MA, Weng DE, et al. A Phase I study of the SMAC-Mimetic Birinapant in adults with refractory solid tumors or lymphoma. Mol Cancer Ther. 2015;14:2569-75.

44. Srivastava AK, Jaganathan S, Stephen L, Hollingshead MG, Layhee A, Damour E, et al. Effect of a Smac Mimetic (TL32711, Birinapant) on the apoptotic program and apoptosis biomarkers examined with validated multiplex immunoassays fit for clinical use. Clin Cancer Res. 2016;22:1000-10.

45. Imoto I, Tsuda H, Hirasawa A, Miura M, Sakamoto M, Hirohashi $\mathrm{S}$, et al. Expression of cIAP1, a target for $11 \mathrm{q} 22$ amplification, correlates with resistance of cervical cancers to radiotherapy. Cancer Res. 2002;62:4860-6.

46. Imoto I, Yang ZQ, Pimkhaokham A, Tsuda H, Shimada Y, Imamura $\mathrm{M}$, et al. Identification of cIAP1 as a candidate target gene within an amplicon at 11q22 in esophageal squamous cell carcinomas. Cancer Res. 2001;61:6629-34.

47. Beug ST, Tang VA, Lacasse EC, Cheung HH, Beauregard CE, Brun J, et al. Smac mimetics and innate immune stimuli synergize to promote tumor death. Nat Biotechnol. 2014;32:182-90.

48. Cai J, Lin Y, Zhang H, Liang J, Tan Y, Cavenee WK, et al. Selective replication of oncolytic virus M1 results in a bystander killing effect that is potentiated by Smac mimetics. Proc Natl Acad Sci USA. 2017;114:6812-17.

49. Dobson CC, Naing T, Beug ST, Faye MD, Chabot J, St-Jean M, et al. Oncolytic virus synergizes with Smac mimetic compounds to induce rhabdomyosarcoma cell death in a syngeneic murine model. Oncotarget. 2017;8:3495-508.
50. Brumatti G, Ma C, Lalaoui N, Nguyen NY, Navarro M, Tanzer MC, et al. The caspase- 8 inhibitor emricasan combines with the SMAC mimetic birinapant to induce necroptosis and treat acute myeloid leukemia. Sci Transl Med. 2016;8:339ra69.

51. Lawlor KE, Feltham R, Yabal M, Conos SA, Chen KW, Ziehe S, et al. XIAP loss triggers RIPK3- and Caspase-8-Driven IL-1beta activation and cell death as a consequence of TLR-MyD88induced cIAP1-TRAF2 degradation. Cell Rep. 2017;20:668-82.

52. Lawlor KE, Khan N, Mildenhall A, Gerlic M, Croker BA, D'Cruz AA, et al. RIPK3 promotes cell death and NLRP3 inflammasome activation in the absence of MLKL. Nat Commun. 2015;6:6282.

53. Vince JE, Wong WW, Gentle I, Lawlor KE, Allam R, O'Reilly L, et al. Inhibitor of apoptosis proteins limit RIP3 kinase-dependent interleukin-1 activation. Immunity. 2012;36:215-27.

54. Wicki S, Gurzeler U, Wong WW-L, Jost PJ, Bachmann D, Kaufmann T. Loss of XIAP facilitates switch to TNF $\alpha$-induced necroptosis in mouse neutrophils. Cell Death Dis. 2016;7:e2422.

55. Yabal M, Müller N, Adler H, Knies N, Groß CJ, Damgaard RB, et al. XIAP restricts TNF- and RIP3-dependent cell death and inflammasome activation. Cell Rep. 2014;7:1796-808.

56. Chesi M, Mirza NN, Garbitt VM, Sharik ME, Dueck AC, Asmann $\mathrm{YW}$, et al. IAP antagonists induce anti-tumor immunity in multiple myeloma. Nat Med. 2016;22:1411-20.

57. Beug ST, Beauregard CE, Healy C, Sanda T, St-Jean M, Chabot J, et al. Smac mimetics synergize with immune checkpoint inhibitors to promote tumour immunity against glioblastoma. Nat Commun. 2017;8:14278.

58. Kearney CJ, Lalaoui N, Freeman AJ, Ramsbottom KM, Silke J, Oliaro J. PD-L1 and IAPs co-operate to protect tumors from cytotoxic lymphocyte-derived TNF. Cell Death Differ. 2017;24:1705-16.

59. Oakes SR, Vaillant F, Lim E, Lee L, Breslin K, Feleppa F, et al. Sensitization of BCL-2-expressing breast tumors to chemotherapy by the BH3 mimetic ABT-737. Proc Natl Acad Sci USA. 2012;109:2766-71.

60. Liao Y, Smyth GK, Shi W. The subread aligner: fast, accurate and scalable read mapping by seed-and-vote. Nucleic Acids Res. 2013;41:e108.

61. Liao Y, Smyth GK, Shi W. featureCounts: an efficient general purpose program for assigning sequence reads to genomic features. Bioinformatics. 2014;30:923-30.

62. Robinson MD, Oshlack A. A scaling normalization method for differential expression analysis of RNA-seq data. Genome Biol. 2010;11:R25.

63. Ritchie ME, Phipson B, Wu D, Hu Y, Law CW, Shi W, et al. limma powers differential expression analyses for RNAsequencing and microarray studies. Nucleic Acids Res. 2015;43: e47.

64. Law CW, Chen Y, Shi W, Smyth GK. voom: Precision weights unlock linear model analysis tools for RNA-seq read counts. Genome Biol. 2014;15:R29.

65. Wu D, Lim E, Vaillant F, Asselin-Labat ML, Visvader JE, Smyth GK. ROAST: rotation gene set tests for complex microarray experiments. Bioinformatics. 2010;26:2176-82. 